\title{
Simultaneous cardio-cerebral embolization associated with atrial fibrillation: a case report
}

\author{
Soichiro Abe ${ }^{1,2}$, Kanta Tanaka ${ }^{1 *}$ (D), Hiroshi Yamagami ${ }^{1}, K^{2}$ azutaka Sonoda ${ }^{1}$, Hiroya Hayashi ${ }^{3}$, Shuichi Yoneda ${ }^{3}$, \\ Kazunori Toyoda ${ }^{4}$ and Masatoshi Koga ${ }^{4}$
}

\begin{abstract}
Background: Simultaneous cerebral and myocardial infarction is called cardiocerebral infarction (CCI), and is rarely encountered. Because of the narrow time window and complex pathophysiology, $\mathrm{CCl}$ is challenging to immediately diagnose and treat.

Case presentation: A 73-year-old woman suddenly developed right hemiplegia and severe aphasia. Twelvelead electrocardiography showed tachycardic atrial fibrillation without any significant ST-T change. Magnetic resonance imaging revealed a proximal middle cerebral artery occlusion. She was immediately treated with alteplase at the dosage approved for ischemic stroke followed by mechanical thrombectomy as bridging therapy, and complete recanalization was achieved. Aphasia improved and she began to complain of chest pain, and reported that she had experienced chest discomfort just prior to right limb weakness. Coronary angiography showed a partial filling defect in the right coronary artery with rapid and adequate distal flow, for which percutaneous coronary intervention was not required. Alteplase was suggested to have effectively resolved the coronary emboli. The occlusions of the cerebral and coronary arteries were assumed to have occurred nearly simultaneously and cardiogenic embolism due to atrial fibrillation was considered as the most likely etiology.

Conclusions: As seen in the present case, $\mathrm{CCl}$ may benefit from immediate treatment with intravenous tissue plasminogen activator (IV-tPA). Although which of percutaneous coronary intervention or cerebral thrombectomy should be performed first remains unclear, we must decide whether to rescue the brain or heart first in each patient within a limited window of time. This dilemma has recently become evident in this era with mechanical thrombectomy strongly established as an effective intervention for acute ischemic stroke. Close cooperation between stroke physicians and cardiologists is becoming more important.
\end{abstract}

Keywords: Cerebral embolization, Coronary embolization, Cardiocerebral infarction, Atrial fibrillation, Recanalization

\section{Background}

Simultaneous cerebral and myocardial infarction is called cardiocerebral infarction (CCI), and is rarely encountered [1]. Because of the narrow time window and the complex pathophysiology, $\mathrm{CCI}$ is challenging to immediately diagnose and treat. Here, we report

\footnotetext{
* Correspondence: tanaka19830311kanta@gmail.com

'Division of Stroke Care Unit, National Cerebral and Cardiovascular Center,

6-1 Kishibe Shinmachi, Suita 564-8565, Japan

Full list of author information is available at the end of the article
}

the case of a patient with simultaneous cerebral and coronary embolization associated with atrial fibrillation, with consideration of the management strategy for CCI.

\section{Case presentation}

A 73-year-old woman suddenly developed right hemiplegia and severe aphasia and was transported to our emergency service $47 \mathrm{~min}$ after onset. Her medical history included hypertension and paroxysmal atrial fibrillation.

(c) The Author(s). 2019 Open Access This article is distributed under the terms of the Creative Commons Attribution 4.0 International License (http://creativecommons.org/licenses/by/4.0/), which permits unrestricted use, distribution, and 
Anticoagulants have been discontinued because of a few episodes of falls although she had previously received oral anticoagulation. Blood pressure was $105 / 75 \mathrm{mmHg}$ without any significant difference between right and left limbs. No cardiac murmurs were audible. Twelve-lead electrocardiography (ECG) showed tachycardic atrial fibrillation with a heart rate of 150 beats/min but no significant ST-T changes, although the baseline was undulating due to patient movement (Fig. 1). Glasgow Coma Scale score was 9 (E4V1M4). The patient was mute and could not follow any commands. She presented with right hemiplegia and showed left-ward conjugate eye deviation that could not be overcome with oculocephalic stimulation. The National Institutes of Health Stroke Scale score was 21. Blood glucose level was $189 \mathrm{mg} / \mathrm{dL}$, serum creatinine level was $0.66 \mathrm{mg} / \mathrm{dL}$, hemoglobin was $10.8 \mathrm{mg} / \mathrm{dL}$, and platelet count was $16.9 \times 10^{4} / \mu \mathrm{L}$. No abnormalities were evident on chest roentgenogram.

We immediately performed magnetic resonance imaging following the stroke management protocol in our institute. Diffusion-weighted imaging showed hyperintense lesions at the left basal ganglia and corona radiata (Fig. 2a, b). A susceptibility vessel sign was seen in the proximal portion of the left middle cerebral artery (Fig. 2c). Magnetic resonance angiography revealed proximal occlusion of the left middle cerebral artery (Fig. 2d). Alteplase at a dose of $0.6 \mathrm{mg} / \mathrm{kg}$ (the dose approved in Japan) was administered $43 \mathrm{~min}$ after hospital arrival [2, 3], immediately followed by endovascular thrombectomy as bridging therapy [4].
After thrombectomy with a stent retriever (Solitaire 2, $4 \times 20 \mathrm{~mm}$; Medtronic, California, USA), complete recanalization was obtained $95 \mathrm{~min}$ after hospital arrival (Fig. 2e, f). Cardiac rhythm monitoring during the endovascular procedure did not show significant findings other than the tachycardic atrial fibrillation.

Aphasia and right hemiplegia improved immediately after completing mechanical thrombectomy and she began to complain of chest pain. A detailed medical history was elicited and revealed that she experienced chest discomfort just prior to the development of weakness in the right extremities. No symptoms suggestive of angina pectoris had been present prior to this episode of chest discomfort. Twelve-lead ECG showed ST elevation at II, III, and aVF and ST depression at V2-V6 (Fig. 3a). Transthoracic echocardiogram showed decreased motion of the posterior wall and interventricular septum, and serum troponins were elevated. Coronary angiography revealed a filling defect in the right coronary artery, but distal flow was rapid and adequate (Fig. 3b). Distal occlusions were identified in the left circumflex small branch and the diagonal branch (Fig. 3c). No stenotic lesions suggestive of atherosclerotic pathology were identified. Because we considered that myocardial perfusion was sufficient overall, percutaneous coronary intervention (PCI) was not performed.

The occlusions of the left middle cerebral artery and coronary arteries were assumed to have occurred nearly simultaneously, with cardiogenic embolism due to atrial fibrillation considered as the most likely etiology [5]. No deep vein thrombosis of the lower limbs was evident on

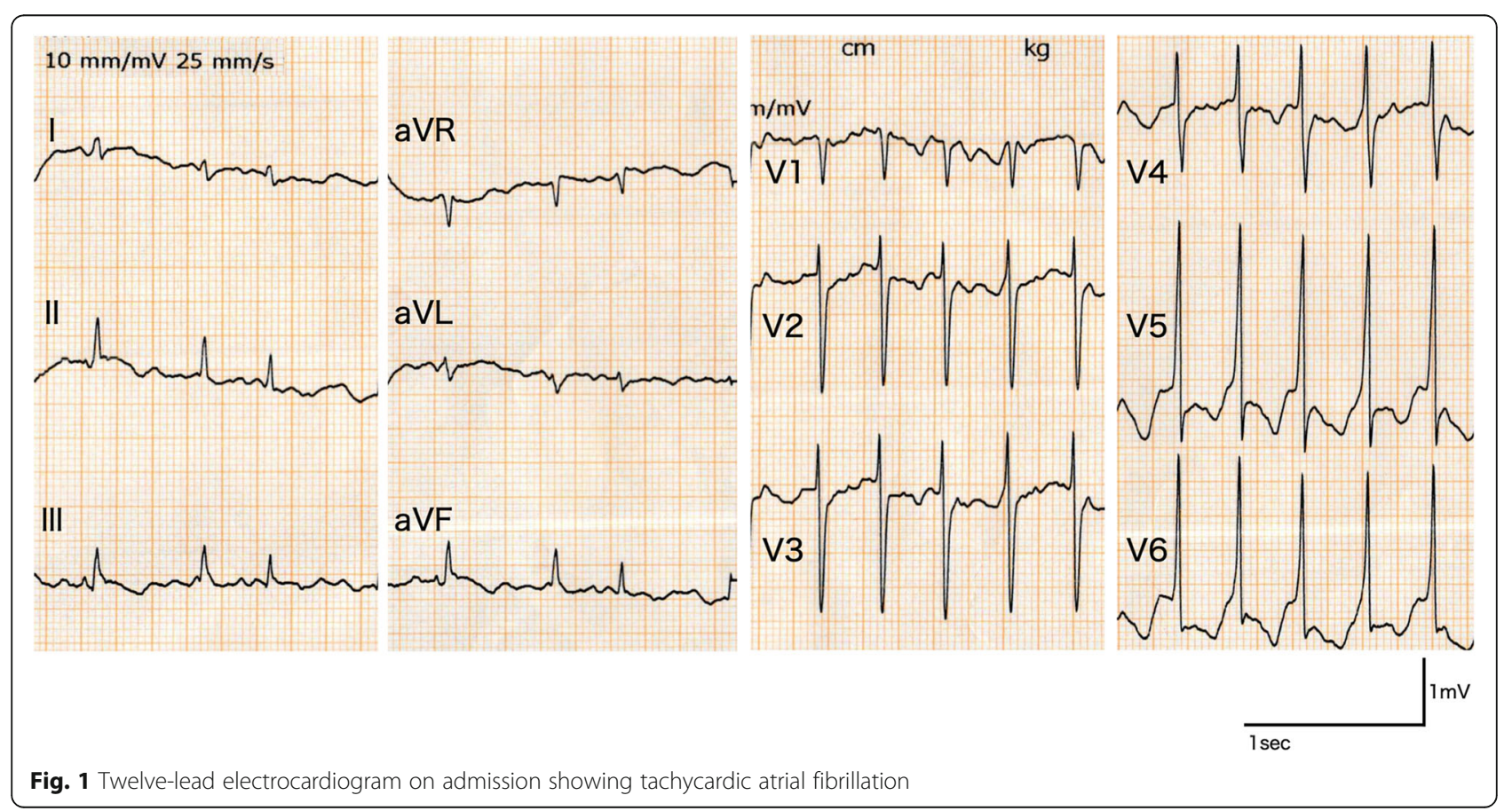



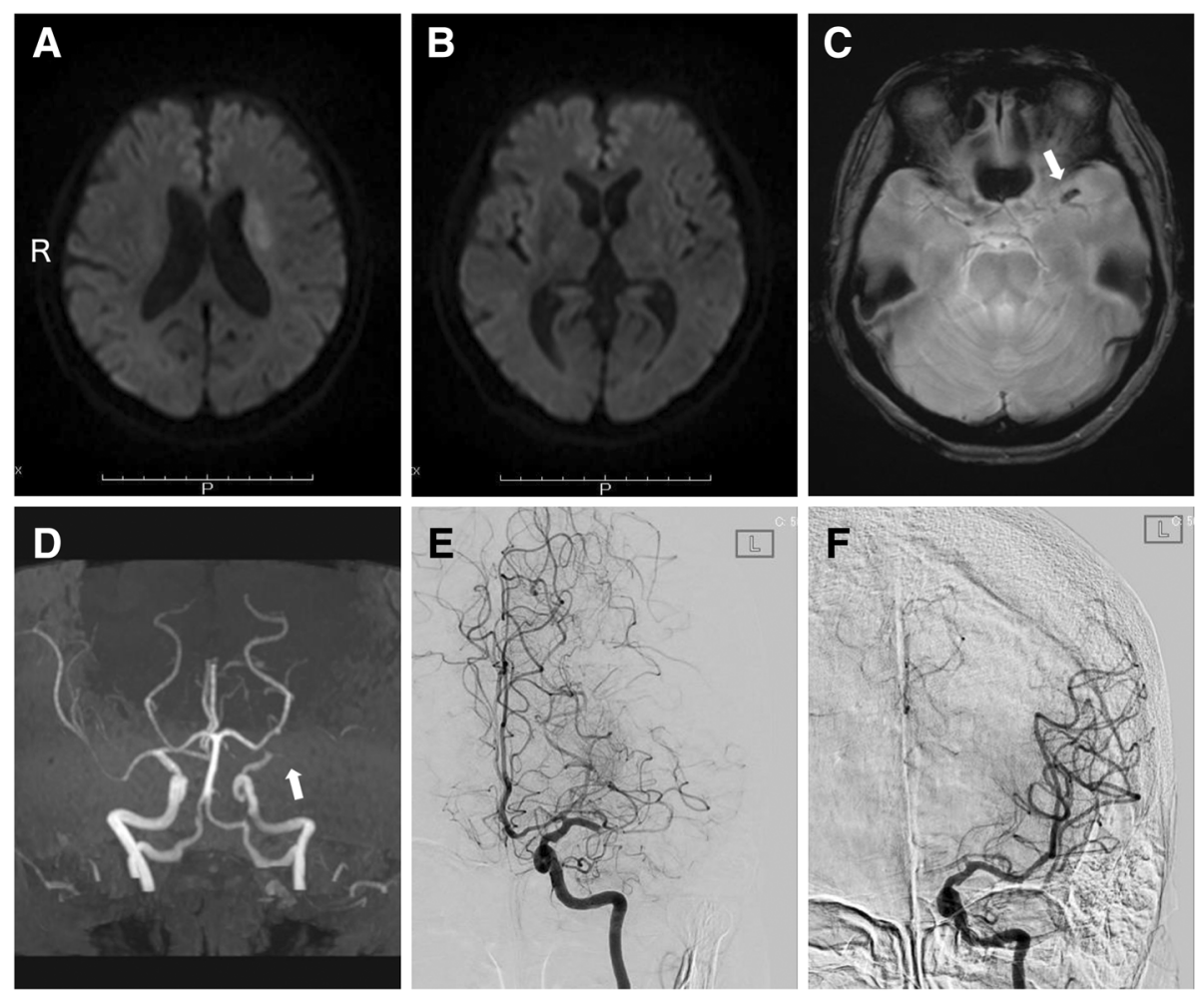

Fig. 2 Diffusion-weighted magnetic resonance imaging showing acute infarction at the left corona radiata (a) and left basal ganglia (b). (c) T2*weighted imaging showing a susceptibility vessel sign (white arrow) in the left middle cerebral artery. (d) Magnetic resonance angiography showing proximal occlusion (white arrow) of the left middle cerebral artery. (e) Anteroposterior view of a selective left internal carotid angiogram showing occlusion of the left middle cerebral artery. (f) Left internal carotid angiogram, anteroposterior view, showing complete recanalization of the left middle cerebral artery

ultrasonography. On day 5 after admission, oral rivaroxaban was started at a dose of $15 \mathrm{mg} /$ day (the standard dose in Japan) [6]. Bisoprolol $(0.625 \mathrm{mg} /$ day) was initiated for rate-control purposes. The patient was discharged for rehabilitation on day 22. The modified Rankin Scale score at 3 months after stroke onset was 2 .
The patient experienced no recurrence of cerebral or myocardial infarction at 6 months after discharge.

\section{Discussion and conclusions}

We have presented herein a case of atrial fibrillationassociated CCI in which nearly simultaneous embolization

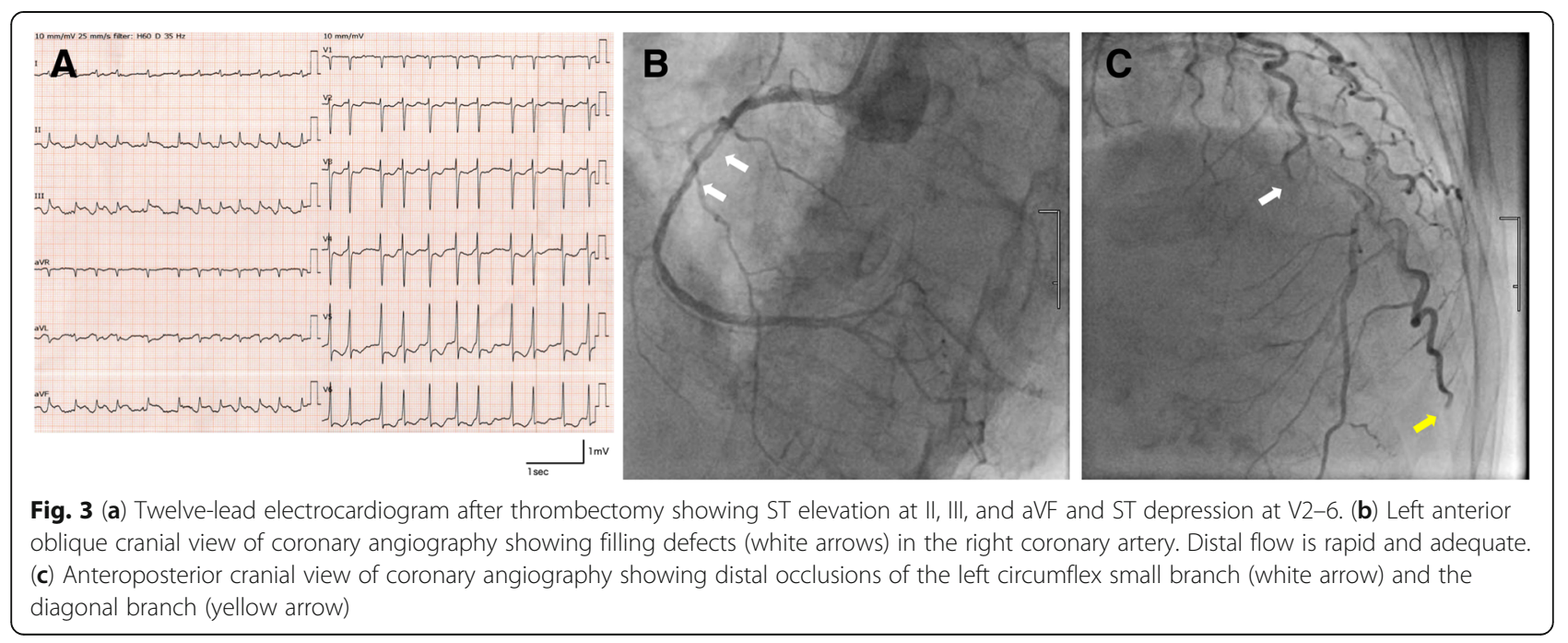


of the cerebral and coronary arteries occurred. The term CCI was coined by Omar et al. [1], and this rare condition has a reported frequency of $0.009-0.52 \%$ of ischemic strokes [7-9]. Recommendations or guidelines for the management of CCI remain lacking because of the rarity and variable pathophysiology of this clinical scenario. Among the 12 reported patients with detailed clinical information, no patient received oral anticoagulation prior to the event and 3 patients were newly diagnosed as having atrial fibrillation $[1,7,10-14]$. In our patient, appropriate anticoagulation might have prevented the event of CCI. Risk-benefit profile of oral anticoagulation for patients with tendency to fall should be elucidated further [15].

In our patient, chest discomfort was not initially detected due to the severe aphasia. The initial 12-lead ECG and subsequent monitoring of cardiac rhythm did not show any marked ST-T changes, as these would have been obscured by the tachycardic atrial fibrillation and the wandering baseline artifact, both of which are frequently encountered in emergency settings. Although evaluation of serum cardiac enzymes might have allowed earlier diagnosis of coronary embolization, routine monitoring of cardiac enzymes is not clearly recommended by major guidelines for acute ischemic stroke [16, 17]. In cases of cerebral embolism, it is important to constantly keep in mind the possibility of concomitant myocardial infarction, because the diagnosis of myocardial infarction could be delayed due to several factors, including impaired consciousness, aphasia, or reduced pain sensation.

In our case, cerebral embolism was treated first with intravenous tissue plasminogen activator (IV-tPA) and mechanical thrombectomy, followed by coronary angiography, which did not suggest any requirement for PCI. Coronary angiography suggested that alteplase at the dosage approved for ischemic stroke had resolved the coronary emboli. Because IV-tPA is effective for both cerebral and myocardial infarction, $\mathrm{CCI}$ is likely to benefit from immediate treatment with IV-tPA prior to endovascular therapy. Although the recommended dosages of IV-tPA differ between cerebral and myocardial ischemia, in 6 previously reported cases of CCI treated with IVtPA therapy, the dosage of IV-tPA applied was that used for acute ischemic stroke $[7,10,11][12,13]$. When treating CCI patients with IV-tPA, close attention is required because the etiology of CCI includes aortic dissection $[18,19]$, which is a contraindication for IV-tPA. Furthermore, fatal complications such as cardiac rupture and tamponade may occur after IV-tPA [20, 21].

A dilemma exists regarding endovascular therapy: although the occluded cerebral and coronary arteries have to be recanalized as soon as possible in the case of CCI, prioritizing one therapy leads to delays in the other. In previous studies, four patients were treated with both PCI and cerebral thrombectomy [7, 14], with cerebral thrombectomy carried out first in 2 patients. One patient showed severe disturbance of consciousness due to the proximal posterior cerebral artery occlusion [3] and another patient had no abnormal findings on ECG in the emergency room [18]. Regarding the 2 patients in whom PCI was implemented first, circulatory dynamics were unstable. Although which of PCI or cerebral thrombectomy should be performed first remains unclear, a decision algorithm for acute management of CCI has been proposed [11], in which cerebral thrombectomy can be prioritized if the circulatory dynamics are stable. Nonetheless, we must decide to rescue the brain or heart first in each patient within a limited window of time. This dilemma has become evident in the present era with mechanical thrombectomy strongly established as an effective intervention for acute ischemic stroke. Close cooperation between stroke physicians and cardiologists is thus becoming more important.

In conclusion, simultaneous cerebral and coronary embolism is rare and its prompt and appropriate management is difficult. Coexistence of coronary embolization should be considered when planning the treatment strategy for acute cerebral embolism. Further cases need to be studied to resolve the dilemma inherent in the recanalization strategy for CCI.

\section{Abbreviations}

CCI: cardiocerebral infarction; ECG: electrocardiography; IV-tPA: intravenous tissue plasminogen activator; $\mathrm{PCl}$ : percutaneous coronary intervention

\section{Acknowledgements}

The authors would like to thank Dr. Masayuki Shiozawa, Dr. Muneaki Kikuno, Dr. Teppei Kamimura, Dr. Kyohei Fujita, and Dr. Masafumi Ihara for their academic support.

\section{Authors' contributions}

$\mathrm{SA}, \mathrm{KT} 1, \mathrm{KS}$, and $\mathrm{HY}$ were responsible for the clinical management of the patient. $\mathrm{HH}$ and SY were cardiologists and participated in diagnosing and treating the acute myocardial infarction. SA and KT1 were the main contributors to the writing of the manuscript. KT2 and MK provided intellectual input to the background and discussion. All authors read and approved the final manuscript.

\section{Funding \\ None.}

Availability of data and materials

All the data generated or analyzed during this study are included in this article.

Ethics approval and consent to participate

Not applicable.

\section{Consent for publication}

Written informed consent was obtained from the patient and her husband for publication of this case report and the accompanying images.

\section{Competing interests}

The authors declare that they have no competing interests.

\section{Author details}

'Division of Stroke Care Unit, National Cerebral and Cardiovascular Center, 6-1 Kishibe Shinmachi, Suita 564-8565, Japan. ${ }^{2}$ Department of Neurology, 
National Cerebral and Cardiovascular Center, Suita, Japan. ${ }^{3}$ Department of Cardiovascular Medicine, National Cerebral and Cardiovascular Center, Suita, Japan. ${ }^{4}$ Department of Cerebrovascular Medicine, National Cerebral and Cardiovascular Center, Suita, Japan.

Received: 4 February 2019 Accepted: 1 July 2019

Published online: 05 July 2019

\section{References}

1. Omar HR, Fathy A, Rashad R, Helal E. Concomitant acute right ventricular infarction and ischemic cerebrovascular stroke; possible explanations. Int Arch Med. 2010;3:25

2. Minematsu K, Toyoda K, Hirano T, Kimura K, Kondo R, Mori E, et al. Guidelines for the intravenous application of recombinant tissue-type plasminogen activator (alteplase), the second edition, October 2012: a guideline from the Japan stroke society. J Stroke Cerebrovasc Dis. 2013;22: 571-600.

3. Yamaguchi T, Mori E, Minematsu K, Nakagawara J, Hashi K, Saito I, et al. Alteplase at $0.6 \mathrm{mg} / \mathrm{kg}$ for acute ischemic stroke within 3 hours of onset: Japan Alteplase clinical trial (J-ACT). Stroke. 2006;37:1810-5.

4. Mistry EA, Mistry AM, Nakawah MO, Chitale RV, James RF, Volpi JJ, et al. Mechanical Thrombectomy outcomes with and without intravenous thrombolysis in stroke patients: a meta-analysis. Stroke. 2017;48:2450-6.

5. Shibata T, Kawakami S, Noguchi T, Tanaka T, Asaumi Y, Kanaya T, et al. Prevalence, clinical features, and prognosis of acute myocardial infarction attributable to coronary artery embolism. Circulation. 2015; 132:241-50.

6. Hori M, Matsumoto M, Tanahashi N, Momomura S, Uchiyama S, Goto S, et al. Rivaroxaban vs. warfarin in Japanese patients with atrial fibrillation. Circ J. 2012;76:2104-11.

7. Yeo LLL, Andersson T, Yee KW, Tan BYQ, Paliwal P, Gopinathan A, et al. Synchronous cardiocerebral infarction in the era of endovascular therapy: which to treat first? J Thromb Thrombolysis. 2017;44:104-11.

8. Khechinashvili G, Asplund K. Electrocardiographic changes in patients with acute stroke: a systematic review. Cerebrovasc Dis. 2002;14:67-76.

9. Kawamura A, Lombardi DA, Tilem ME, Gossman DE, Piemonte TC, Nesto RW. Stroke complicating percutaneous coronary intervention in patients with acute myocardial infarction. Circ J. 2007;71:1370-5.

10. González-pacheco H, Méndez-domínguez A, Vieyra-herrera G, Azar-manzur F, Meave-gonzález A, Rodríguez-zanella $H$, et al. Reperfusion strategy for simultaneous ST-segment elevation myocardial infarction and acute ischemic stroke within a time window. Am J Emerg Med. 2014;32:1157.e1-4.

11. Kijpaisalratana N, Chutinet A, Suwanwela NC. Hyperacute simultaneous cardiocerebral infarction: rescuing the brain or the heart first? Front Neurol. 2017:8:1-7.

12. Maciel R, Palma R, Sousa P, Ferreira F, Nzwalo H. Acute stroke with concomitant acute myocardial infarction: will you thrombolyse? J Stroke. 2015;17:84-6.

13. Tanaka K, Nakayasu H, Suto Y, Takahashi S, Kageshima K, Nakashima K. Simultaneous acute ischemic stroke and acute myocardial infarction treated with intravenous t-PA. Jpn J Stroke. 2017;39:205-9.

14. Tokuda K, Shindo S, Yamada K, Shirakawa M, Uchida K, Horimatsu T, et al. Acute embolic cerebral infarction and coronary artery embolism in a patient with atrial fibrillation caused by similar thrombi. J Stroke Cerebrovasc Dis. 2016;25:1797-9.

15. Chiu AS, Jean RA, Fleming M, Pei KY. Recurrent falls among elderly patients and the impact of anticoagulation therapy. World J Surg. 2018;42:3932-8.

16. Powers WJ, Rabinstein AA, Ackerson T, Adeoye OM, Bambakidis NC, Becker K, et al. 2018 guidelines for the early management of patients with acute ischemic stroke: a guideline for healthcare professionals from the American Heart Association/American Stroke Association. Stroke. 2018;49:e46-110.

17. Ringleb PA, Bousser MG, Ford G, Bath P, Brainin M, Caso V, et al. Guidelines for management of ischaemic stroke and transient ischaemic attack 2008. Cerebrovasc Dis. 2008;25:457-507.

18. Cook J, Aeschlimann S, Fuh A, Kohmoto T, Chang SM. Aortic dissection presenting as concomitant stroke and STEMI. J Hum Hypertens. 2007;21: 818-21.

19. Kawano H, Tomichi Y, Fukae S, Koide Y, Toda G, Yano K. Aortic dissection associated with acute myocardial infarction and stroke found at autopsy. Intern Med. 2006;45:957-62.
20. Dhand A, Nakagawa K, Nagpal S, Gelfand JM, Kim AS, Smith WS, et al. Cardiac rupture after intravenous t-PA administration in acute ischemic stroke. Neurocrit Care. 2010;13:261-2.

21. Tsugita N. An autopsy case of cardiac rupture after intravenous rt-PA administration for acute ischemic stroke. Jpn J Stroke. 2011;33:241-5.

\section{Publisher's Note}

Springer Nature remains neutral with regard to jurisdictional claims in published maps and institutional affiliations.
Ready to submit your research? Choose BMC and benefit from:

- fast, convenient online submission

- thorough peer review by experienced researchers in your field

- rapid publication on acceptance

- support for research data, including large and complex data types

- gold Open Access which fosters wider collaboration and increased citations

- maximum visibility for your research: over $100 \mathrm{M}$ website views per year

At $\mathrm{BMC}$, research is always in progress.

Learn more biomedcentral.com/submissions 